\title{
Effect of increased inspired oxygen on exercise performance in patients with heart
}

\section{failure and normal ejection fraction}

Parin Shah MbChB, MRCP, Pierpaolo Pellicori MD, FESC, Stella Rimmer, Alan S Rigby MSc, Andrew L Clark MA, MD, FRCP.

Department of Cardiology, Hull York Medical School, Hull and East Yorkshire Medical Research and Teaching Centre, Castle Hill Hospital, Cottingham, Kingston upon Hull, HU16 5JQ, UK

The authors takes responsibility for all aspects of the reliability and freedom from bias of the data presented and their discussed interpretation

\section{Address for correspondence:}

Parin Shah,

Department of Cardiology, Hull York Medical School,

Hull and East Yorkshire Medical Research and Teaching Centre,

Castle Hill Hospital, Cottingham, Kingston upon Hull, HU16 5JQ, UK

Email: parinshah194@yahoo.co.uk,parin.shah@hey.nhs.uk

Telephone number: +441482461811

Fax number: +441482461808

Funding: none

Conflict of interest: none

Keywords: heart failure with normal ejection fraction, exercise, oxygen 


\begin{abstract}
Introduction: We investigated whether increased concentrations of inspired oxygen $\left(\mathrm{FiO}_{2}\right)$ affects exercise tolerance in patients with heart failure and normal ejection fraction (HeFNEF).
\end{abstract}

Methods: 46 patients (mean age 75 years (63\% male) and median NTproBNP 1432 (interquartile range: 543-2378 ng/l)) with HeFNEF (defined as signs or symptoms of heart failure requiring treatment with diuretics, with a left ventricular ejection fraction of more than 45\% by echocardiography and amino terminal pro brain natriuretic peptide (NTproBNP) $>220$ ng/l) completed three maximal incremental exercise tests with different $\mathrm{FiO}_{2}$ (21\%, 28\% and $40 \%$ ) in random order. $\mathrm{FiO}_{2}$ was controlled by investigator but blinded to patients. The primary outcome was exercise time (ET).

Results: Increasing $\mathrm{FiO}_{2}$ significantly increased exercise time (522 \pm 180 seconds for $21 \%$ to $543 \pm 176$ seconds, and $542 \pm 177$ seconds, for $28 \%$ and $40 \%$, respectively, $\mathrm{P}=0.04$ ) with no difference in peak workload (57 $\pm 25 \mathrm{~W}, 58 \pm 25 \mathrm{~W}$ and $57 \pm 25 \mathrm{~W}$, for $21 \%$, $28 \%$ and $40 \%$, respectively, $\mathrm{P}=0.50)$. There was an increase in oxygen saturation but no change in peak heart rate with increasing $\mathrm{FiO}_{2}$. Compared to patients with $\mathrm{LVEF} \geq 50 \%$, patients with $\mathrm{LVEF}$ between 45 and 49\% had a significantly greater exercise time and peak workload. There was a correlation between the difference in exercise time between $\mathrm{FiO}_{2} 21 \%$ and $40 \%$ and age; but not with BMI, haemoglobin, creatinine or NTproBNP.

Conclusion: Increasing $\mathrm{FiO}_{2}$ during exertion leads to a small increase in exercise time in patients with HeFNEF. 


\section{Introduction}

Epidemiological studies suggest that heart failure with normal ejection fraction (HeFNEF) accounts for almost $50 \%$ of patients with heart failure (HF), and its prevalence is increasing. ${ }^{1,2,3}$ Compared to patients with heart failure and reduced ejection fraction (HeFREF), those with HeFNEF are usually older and have more comorbidities, ${ }^{4}$ which plays a significant role in the development and/or worsening of HF symptoms and substantially contributes to the adverse prognosis of patients with HeFNEF. HeFNEF is a heterogeneous clinical syndrome which can be difficult to diagnose and treat. ${ }^{4}$

Clinical trials have failed to demonstrate that any pharmacological treatment improves outcomes for patients with HeFNEF. ${ }^{5,6,7,8,9,10}$ However, another important aim of treatment is to alleviate symptoms and to improve wellbeing. ${ }^{11}$ The clinical hallmark of HeFNEF is exertional breathlessness, at least partially due to an abnormal increase in left atrial pressure during exercise. ${ }^{4}$ Reduction in delivery of oxygen to the periphery and myocardium might contribute to, and aggravate, breathlessness and fatigue. ${ }^{4}$ Small trials suggest that increasing inspired oxygen concentration during exercise might prolong exercise time and improve symptoms in patients with HeFREF or pulmonary hypertension, ${ }^{12,13,14}$ but the effect on patients with HeFNEF is unknown.

We aimed to assess the effects of increasing inspired oxygen fraction $\left(\mathrm{FiO}_{2}\right)$ on exercise capacity in patients with HeFNEF.

\section{Methods}

(C) 2018. This manuscript version is made available under the CC-BY-NC-ND 4.0 license http://creativecommons.org/licenses/by-nc-nd/4.0/ 
This was a single centre, randomised, single-blinded, cross-over trial in patients with HeFNEF. The research conforms to the Helsinki declaration. Ethics approval was granted by an external research ethics committee. The trial was registered on the ClinicalTrials.gov website (Identifier: NCT02949531). All patients gave written informed consent.

Ambulatory patients older than 50 years of age attending a community heart failure clinic were considered for the study if they had had a clinical diagnosis of heart failure with a left ventricular ejection fraction (LVEF) by echocardiography $\geq 45 \%$ and a plasma concentration of amino terminal pro B type natriuretic peptide (NTproBNP) $\geq 220 \mathrm{ng} / \mathrm{l} .{ }^{15}$ Patients had to be taking a diuretic. Patients unable to exercise, and those who had severe mitral or aortic valve disease, haemoglobin $<100 \mathrm{~g} / \mathrm{l}$, estimated glomerular filtration rate $<30 \mathrm{ml} / \mathrm{min} / 1.73 \mathrm{~m}^{2}$ ), or severe chronic obstructive pulmonary disease ( $\mathrm{FEV}_{1}$ less than $50 \%$ predicted) were excluded from the study.

\section{Exercise protocol}

Patients undertook three maximal incremental exercise tests on a stationary cycle using a standardised exercise protocol. Patients cycled at 60 revolutions per minute starting from 0 watts for 4 minutes; subsequently, resistance increased by 10 watts/minute. Patients were encouraged to exercise to their maximum capacity. At the end of the exercise test, the reason for stopping and modified Borg score were recorded.

Inspired oxygen fraction $\left(\mathrm{FiO}_{2}\right)$ was administered at different concentrations (21\%, 28\% and $40 \%$ ) in a random sequence which was computer generated. All three oxygen concentrations were delivered via a Venturi mask. This allowed the investigator to control the oxygen 
concentration administered whilst the patients and the technicians conducting the test were blinded to FiO2. During the exercise test, blood pressure, oxygen saturation, heart rate and rhythm were continuously monitored. The three exercise tests were conducted at approximately weekly intervals.

The primary endpoint was exercise time (ET; seconds). Secondary end points included: peak workload (watts), modified Borg score, peak heart rate (beats per minute), and peak arterial oxygen saturation $\left(\mathrm{O}_{2}\right.$ sat; percentage).

\section{Statistical analysis}

Categorical data are presented as number and percentages; normally distributed continuous data as mean \pm standard deviation (SD) and non-normally distributed continuous variables as median and interquartile range.

Between-group means of the primary and secondary endpoints were compared using analysis of variance (ANOVA). The method uses 'least squares' to fit linear models. We used oneway ANOVA with repeated measures on dose-group. An underlying assumption of the F test is independence of observations. In a repeated measures design, this assumption is almost certainly violated (observations from the same subject are likely to be correlated). To overcome this, we used a correction factor (a number have been proposed in the literature) to the degrees-of-freedom for the F test. We chose one developed by Box which is conservative in a statistical sense (if significant by Box it will be significant by the rest). ${ }^{16}$ Other assumptions of ANOVA were met. Paired t-tests were then used to compare the primary and secondary endpoints between exercise tests. 
Sub-group analysis of the primary and secondary endpoints were pre-specified and used to explore the relation between age, haemoglobin, creatinine, NTproBNP, body mass index (BMI), sex, the use of a walking aid and heart rhythm (atrial fibrillation vs sinus rhythm) and the end points. The current European Society of Cardiology guidelines on heart failure set an LVEF cut-off at $50 \%$ for diagnosing HeFNEF, so we re-analysed the results for patients above and below this LVEF cut-off. ${ }^{11}$ Primary and secondary endpoints are shown in boxplots. All analyses were performed on SPSS (V 23.0) and Stata statistical computer packages. A statistical significance was assumed at $\mathrm{P}<0.05$ (two tailed).

There were no missing values for exercise time so an analysis of missing data by multiple imputations was unnecessary. ${ }^{17}$

\section{Results}

Of the 50 patients enrolled, 46 patients completed the three visits, and 4 withdrew.

(Supplementary Figure 1).The baseline characteristics of the 46 patients who completed the study are shown in table 1 . Most patients were men, overweight and had NYHA class II symptoms. Compared to patients with LVEF $\geq 50 \%$, patients with LVEF between 45 and 49\% had a significantly higher NTproBNP and creatinine, and a lower haemoglobin.

Increasing $\mathrm{FiO}_{2}$ led to an increase in exercise time of approximately 20 seconds $(\mathrm{P}=0.04)$. There was no dose response relation: exercise time was increased by the same amount during both tests with increased $\mathrm{FiO}_{2}$ compared with 21\% $\mathrm{FiO}_{2}$. (Supplementary Table 1; Figure 1) Increasing $\mathrm{FiO}_{2}$ had no effect peak workload $(\mathrm{P}=0.50)$ and modified Borg score $(\mathrm{P}=0.17)$. (Supplementary Table 1; Figure 1) There was no effect of increasing $\mathrm{FiO}_{2}$ on heart rate during 
exercise $(\mathrm{P}=0.65)$, although arterial oxygen saturation throughout exercise was higher with increasing $\mathrm{FiO}_{2}(\mathrm{P}=0.03)$. (Supplementary Table 1)

Patients with LVEF $\geq 50 \%$ had a lower exercise time and peak workload than those with LVEF between $45-49 \%$, but had a slightly greater increase in exercise time with the increase in $\mathrm{FiO}_{2}$ from $21 \%$ to $28 \%$. (Table 2) There was no interaction between increasing $\mathrm{FiO}_{2}$ and exercise capacity in any subgroup. (Supplementary Table 2) There was a positive correlation between the difference in exercise time between $\mathrm{FiO}_{2}$ of $21 \%$ and $40 \%$ and age, but not with BMI, haemoglobin, creatinine or NTproBNP level. (Supplementary Table 3)

\section{Discussion}

We have found that in patients with HeFNEF, increasing oxygen concentration during exercise lead to a small increase in exercise time but had no effect on peak work load.

There are no previous trials of supplementary oxygen during exercise in patients with HeFNEF. Trials of oxygen supplementation during exercise in patients with heart failure with reduced ejection fraction (HeFREF) have yielded mixed results. Moore and colleagues reported a dose dependent increase in exercise time from $548 \pm 275$ seconds on room air to $632 \pm 288$ seconds with $\mathrm{FiO}_{2}$ of $50 \%$ in 12 patients with HeFREF during resistance cycling on a stationary bike to maximum capacity (workload was increased by $15 \mathrm{~W}$ at 2-min intervals). ${ }^{12}$ In contrast, Russell and colleagues found no effect of increasing $\mathrm{FiO}_{2}$ to $60 \%$ on exercise time compared to $21 \% \mathrm{FiO}_{2}$ during symptom limiting resistance cycling on a stationary bike (2-minute resting period followed by increasing workloads of $25 \mathrm{~W}$ every 3 minutes) in 16 patients with LVEF $<35 \% .{ }^{18}$ Restrick found no effect of oxygen delivered at 4 
l/min on 6 minute walk test distance in 12 patients with stable chronic heart failure. ${ }^{19} \mathrm{We}$ studied 31 patients with HeFREF (mean LVEF 31\%) and found that exercise time, maximal workload and maximal metabolic equivalent all increased significantly with increasing $\mathrm{FiO}_{2}$ from $21 \%$, to $28 \%$ and $40 \% \mathrm{FiO}_{2} \cdot{ }^{13}$ In a study of 22 patients with pulmonary hypertension (pulmonary arterial or chronic thrombo-embolic pulmonary hypertension), increasing $\mathrm{FiO}_{2}$ to 50\% approximately doubled exercise time (from $571 \pm 443$ seconds to $1242 \pm 514$ seconds) and maximal work rate $(113 \pm 38 \mathrm{~W}$ to $132 \pm 48 \mathrm{~W}) .{ }^{14}$

Why should increased $\mathrm{FiO}_{2}$ improve exercise performance in patients with HeFREF, but not make a substantial difference in those with HeFNEF? Part of the explanation may be that HeFNEF is something of a diagnostic rag-bag. Extra-cardiac mechanisms may significantly contribute to impaired exercise tolerance in patients with HeFNEF. Those with HeFNEF tend to be older than those with HeFREF, are more likely to be overweight or obese and have chronic lung problems (and other comorbidities including anaemia). ${ }^{20,21}$ Sarcopenia and loss of muscle bulk are common in older people and particularly in patients with HeFNEF. ${ }^{22}$ Patients with HeFNEF are thus, perhaps, more likely to have conditions other than their heart failure that limits exercise, and hence oxygen is less likely to help their exercise performance. In the present study, overall we found no relation between cardiac rhythm or plasma NTproBNP and exercise time. We found, perhaps paradoxically, that patients with LVEF between $45-49 \%$ had a longer ET than those with higher LVEF ( $\geq 50 \%$ ), despite having a significantly greater plasma NTproBNP and lower haemoglobin level. Patients with LVEF between 45-49\% may represent patients who truly have lower exercise capacity due to heart failure rather than those with LVEF $>50 \%$ whose exercise performance might not be entirely related to the heart. ${ }^{23}$ 
The mechanisms causing exercise intolerance in patients with heart failure are complex. ${ }^{24}$ In most stable ambulatory patients with HeFREF, haemodynamics at rest are not substantially impaired. ${ }^{25}$ Major determinants of exercise capacity appear to lie in the periphery, with abnormal skeletal muscle performance being chiefly implicated. The situation may be different in patients with HeFNEF: again, haemodynamics at rest may be normal, but during exercise, there is a disproportionate increase in left atrial pressure, ${ }^{26}$ which contributes to symptoms and is associated with worse long term outcomes. ${ }^{27}$ Trials in patients with HeFNEF which have exercise capacity as a primary endpoint may be likely to fail due to the heterogeneity of the condition.

\section{Limitations}

We only enrolled patients able to exercise. We also only included patients treated with a diuretic; this might have led to a population of patients with HeFNEF with a more severe disease profile. ${ }^{28}$ Monitoring central haemodynamics during exercise testing might have added to the understanding of the causes of exercise intolerance in patients with HeFNEF.

We included some patients who had an LVEF 45\% - 49\% on echocardiography. According to the current ESC HF guidelines, these patients would fall into the newly introduced category of "heart failure with mid-range ejection fraction" (HFmrEF). ${ }^{11}$ Such patients might represent a separate phenotype from patients with HeFNEF.

\section{Conclusions}


Increasing $\mathrm{FiO}_{2}$ during exertion leads to a small increase in exercise time in patients with HeFNEF which is unlikely to be clinically significant.

(C) 2018. This manuscript version is made available under the CC-BY-NC-ND 4.0 license http://creativecommons.org/licenses/by-nc-nd/4.0/ 


\section{References}

\footnotetext{
${ }^{1}$ Owan TE, Hodge DO, Herges RM, Jacobsen SJ, Roger VL, Redfield MM. Trends in prevalence and outcome of heart failure with preserved ejection fraction. $N$ Engl $J$ Med. 2006;355:251-9.
}

${ }^{2}$ Pellicori P, Cleland JG. Heart failure with preserved ejection fraction. Clin Med (Lond). 2014;14:22-8.

${ }^{3}$ van Riet EE, Hoes AW, Wagenaar KP, Limburg A, Landman MA, Rutten FH. Epidemiology of heart failure: the prevalence of heart failure and ventricular dysfunction in older adults over time. A systematic review. Eur J Heart Fail. 2016;18:242-52.

${ }^{4}$ Redfield MM. Heart Failure with Preserved Ejection Fraction. $N$ Engl J Med. 2016;375:1868-1877.

${ }^{5}$ Massie BM, Carson PE, McMurray JJ, Komajda M, McKelvie R, Zile MR, et al; IPRESERVE Investigators. Irbesartan in patients with heart failure and preserved ejection fraction. $N$ Engl J Med. 2008;359:2456-67.

${ }^{6}$ Yusuf S, Pfeffer MA, Swedberg K, Granger CB, Held P, McMurray JJ, et al; CHARM Investigators and Committees. Effects of candesartan in patients with chronic heart failure and preserved left ventricular ejection fraction: the CHARMPreserved Trial. Lancet 2003;362:777-81.

${ }^{7}$ Cleland JGF, Tendera M, Adamus J, Freemantle N, Polonski L, Taylor J. The perindopril in elderly people with chronic heart failure (PEP-CHF) study. Eur Heart J 2006;27:2338-2345. 
${ }^{8}$ Pitt B, Pfeffer MA, Assmann SF, Boineau R, Anand IS, Claggett B, et al; TOPCAT Investigators. Spironolactone for heart failure with preserved ejection fraction. $N$ Engl J Med. 2014;370:1383-92.

${ }^{9}$ Edelmann F, Wachter R, Schmidt AG, Kraigher-Krainer E, Colantonio C, Kamke W, et al; Aldo-DHF Investigators.Effect of spironolactone on diastolic function and exercise capacity in patients with heart failure with preserved ejection fraction: the Aldo-DHF randomized controlled trial. JAMA. 2013;309:781-91.

${ }^{10}$ Cleland JG, Pellicori P, Dierckx R. Clinical trials in patients with heart failure and preserved left ventricular ejection fraction. Heart Fail Clin. 2014;10:511-23.

${ }^{11}$ Ponikowski P, Voors AA, Anker SD, Bueno H, Cleland JG, Coats AJ, et al; Authors/Task Force Members; Document Reviewers. 2016 ESC Guidelines for the diagnosis and treatment of acute and chronic heart failure: The Task Force for the diagnosis and treatment of acute and chronic heart failure of the European Society of Cardiology (ESC)Developed with the special contribution of the Heart Failure Association (HFA) of the ESC. Eur Heart J. 2016; 37:2129-200.

${ }^{12}$ Moore DP, Weston AR, Hughes JM, Oakley CM, Cleland JG, Hughes JMB. Effects of increased inspired oxygen concentrations on exercise performance in chronic heart failure. Lancet 1992;339:850-3.

${ }^{13}$ Koshy A, Pellicori P, Clark AL. The effect of increasing inspired oxygen on exercise performance in patients with chronic heart failure. Heart 2016;0:1-5.

${ }^{14}$ Ulrich S, Hasler ED, Saxer S, Furian M, Müller-Mottet S, Keusch S, et al. Effect of breathing oxygen-enriched air on exercise performance in patients with precapillary 
pulmonary hypertension: randomized, sham-controlled cross-over trial. Eur Heart J. 2017;38:1159-1168.

${ }^{15}$ Paulus WJ1, Tschöpe C, Sanderson JE, Rusconi C, Flachskampf FA, Rademakers FE, et al. How to diagnose diastolic heart failure: a consensus statement on the diagnosis of heart failure with normal left ventricular ejection fraction by the Heart Failure and Echocardiography Associations of the European Society of Cardiology. Eur Heart J. 2007;28:2539-50.

${ }^{16}$ Box GEP. Some theorems on quadratic forms applied in the study of analysis of variance problems. I. Effect of inequality in the one-way classification. Ann. Math. Statist 1954;25:290-302.

${ }^{17}$ Sterne JAC, White IR, Carlin IB, Sprat M, Royston P, Kenward MP, et al. Multiple imputation for missing data in epidemiological and clinical research: potential and pitfalls. BMJ 2009; 338:b2393.

${ }^{18}$ Russell SD, Koshkarian GM, Medinger AE, Carson PE, Higginbotham MB. Lack of effect of increased inspired oxygen concentrations on maximal exercise capacity or ventilation in stable heart failure. Am J Cardiol. 1999;84:1412-6.

${ }^{19}$ Restrick LJ, Davies SW, Noone L, Wedzicha JA. Ambulatory oxygen in chronic heart failure. Lancet. 1992;340:1192-3.

${ }^{20}$ Lam CS, Carson PE, Anand IS, Rector TS, Kuskowski M, Komajda M, et al. Sex differences in clinical characteristics and outcomes in elderly patients with heart failure and preserved ejection fraction: the Irbesartan in Heart Failure with Preserved Ejection Fraction (I-PRESERVE) trial. Circ Heart Fail. 2012;5:571-8.

(C) 2018. This manuscript version is made available under the CC-BY-NC-ND 4.0 license http://creativecommons.org/licenses/by-nc-nd/4.0/ 
${ }^{21}$ Zdziarski LA, Wasser JG, Vincent HK. Chronic pain management in the obese patient: a focused review of key challenges and potential exercise solutions. J Pain Res. 2015;8:63-77.

${ }^{22}$ Bekfani T, Pellicori P, Morris DA, Ebner N, Valentova M, Steinbeck L, et al. Sarcopenia in patients with heart failure with preserved ejection fraction: Impact on muscle strength, exercise capacity and quality of life. Int J Cardiol. 2016;222:41-6.

${ }^{23}$ Basuray A, French B, Ky B, Vorovich E, Olt C, Sweitzer NK, et al. Heart failure with recovered ejection fraction: clinical description, biomarkers, and outcomes. Circulation. 2014;129:2380-7.

${ }^{24}$ Prior DL. Back to the future: re-evaluation of the possible role for oxygen supplementation during exercise in chronic heart failure. Heart. 2016;102:571-2.

${ }^{25}$ Shelton RJ, Ingle L, Rigby AS, Witte KK, Cleland JG, Clark AL. Cardiac output does not limit submaximal exercise capacity in patients with chronic heart failure. Eur J Heart Fail. 2010;12:983-9.

${ }^{26}$ Borlaug BA, Nishimura RA, Sorajja P, Lam CSP, Redfield MM. Exercise hemodynamics enhance diagnosis of early heart failure with preserved ejection fraction. Circ Heart Fail. 2010;3:588-595.

${ }^{27}$ Dorfs S, Zeh W, Hochholzer W, Jander N, Kienzle RP, Pieske B, et al. Pulmonary capillary wedge pressure during exercise and long-term mortality in patients with suspected heart failure with preserved ejection fraction. Eur Heart J. 2014;35:3103-12. 
${ }^{28}$ Pellicori P, Cleland JG, Zhang J, Kallvikbacka-Bennett A, Urbinati A, Shah P, et al. Cardiac Dysfunction, Congestion and Loop Diuretics: their Relationship to Prognosis in Heart Failure. Cardiovasc Drugs Ther. 2016;30:599-609.

\section{Figure Legends}

Figure 1: Increasing $\mathrm{FiO}_{2}$ resulted in a small increased mean exercise time without a significant difference found between $28 \%$ and $40 \%$ as presented by arrows, but no significantly change mean peak workload and mean modified Borg score

Supplementary Figure 1: Total number of patients consented and completed all three visits of the study 